\title{
Thermo-rheological analysis of WMA-additive modified binders
}

\author{
Ahmed Abed (1) - Nick Thom • Davide Lo Presti • Gordon Airey
}

Received: 19 November 2019/Accepted: 7 April 2020/Published online: 29 April 2020

(C) The Author(s) 2020

\begin{abstract}
Thermo-rheological characteristics of unmodified and modified bitumen have significant impacts on the mechanical response of asphalt. This study investigates the impacts of an organic and a chemical Warm Mix Asphalt additive on bitumen thermo-rheological and mechanical characteristics. Modified binders with different concentrations of each additive were studied and analysed comparatively to a 40/60 penetration grade bitumen. Frequency sweep tests were performed at different ageing levels to characterise the Linear Viscoelastic properties. The multiple stress creep and recovery, linear amplitude sweep (LAS) and low temperature creep stiffness tests, together with the Glover-Rowe (G-R) fatigue parameter (determined from fitting of the 2S2P1D model to the complex shear modulus and phase angle master curves) were used to analyse the performance of the binders at critical operating temperatures. The results demonstrated the necessity to analyse the behavior of the studied binders beyond the limits of linear viscoelasticity to better characterise these types of bitumen. The results also indicated that both
\end{abstract}

A. Abed $(\bowtie) \cdot$ N. Thom - D. Lo Presti - G. Airey

Nottingham Transportation Engineering Centre, University of Nottingham, Pavement Research Building, University Park, Nottingham NG7 2Rd, UK

e-mail: ahmed.abed1@nottingham.ac.uk

D. Lo Presti

Department of Engineering, University of Palermo, Palermo, Italy additives retarded bitumen ageing with the organic additive increasing bitumen elastic response while the chemical additive increased its viscous response. The results also showed an excellent correlation between the G-R parameter and LAS results which suggests the ability to use this parameter in characterising fatigue performance of the studied binders. This also suggests that bitumen fatigue life may be improving over time due to the increased elastic behahviour during ageing so long as a certain critical level of ageing is not reached.

Keywords Warm mix asphalt (WMA) additives . Bitumen rheology $\cdot$ Ageing $\cdot$ Fatigue $\cdot$ Rutting $\cdot$ Lowtemperature cracking

\section{Introduction}

Warm mix asphalt (WMA) refers to asphalt mixtures produced at temperatures $10-40{ }^{\circ} \mathrm{C}$ lower than traditional Hot Mix Asphalt (HMA) [1, 2]. WMA was developed in Europe in the 1990s as an alternative to HMA to reduce the environmental impact of the asphalt industry [3]. After the introduction of WMA, several WMA additives and production techniques were developed and used. Currently, there are more than thirty WMA production methods [4] with these methods generally being grouped into three broad 
categories: organic additives, chemical additives and foaming techniques. Organic additives work by reducing bitumen viscosity at temperatures above their melting point. Hence, they can be used to reduce asphalt production temperatures. On the other hand, chemical additives act as a surfactant reducing the frictional forces between the binder and the aggregate, which improves the coating and reduces production temperatures. Foaming techniques follow an entirely different approach by temporarily changing the bitumen's status from liquid into foam by adding $2-5 \%$ cold water. The water boils and is trapped within the bitumen creating the foam which can be mixed with aggregate at a temperature lower than traditional hot mix asphalt [5]. The ultimate aim of these WMA techniques is to enhance asphalt sustainability by lowering the production temperature of asphalt which leads to reduced greenhouse gas emissions and fuel consumption $[6,7]$.

A common element amongst all of the abovementioned WMA technologies is that they work by modifying binder properties such as viscosity or surface tension to achieve this aim [8]. As a consequence of bitumen modification, binder behavior can become more complicated and more challenging to characterise [9, 10]. Additionally, several studies indicated that WMA additives could alter bitumen basic and rheological properties to different extents [11-14]. This means that traditional bitumen characterisation methods such as penetration or viscosity, or the Superpave performance indicators, such as rutting $\left(G^{*} / \sin \delta\right)$ or fatigue cracking $\left(G^{*} \sin \delta\right)$ parameters, may not be valid in characterising the behavior of WMA modified binders since these methods are intrinsically developed for unmodified bitumen [15-17]. Bahia et al. [18] reported that the Superpave rutting and fatigue cracking parameters had a weak correlation with the performance of asphalt mixtures manufactured with modified binders. Airey [19] found that there was no clear relationship between Superpave parameters of modified binders and the actual asphalt performance. Norouzi et al. [20] demonstrated that the Superpave fatigue cracking parameter, $G^{*} \sin \delta$, was unable to characterise fatigue performance of different WMA modified binders. Furthermore, additional studies $[16,21]$ have demonstrated that characterising and predicting bitumen performance based on the LVE properties may also not be valid. These studies indicated that a better prediction of modified bitumen performance could be achieved when bitumen is characterised beyond the limits of linear viscoelasticity.

Furthermore, effects of WMA additives on bitumen characteristics were extensively studied in literature [12, 22-29]. These studies provide a good basis to understand the effects of WMA additives on bitumen characteristics. However, most of these studies were conducted using one dosage of the used additives, or adopted Superpave rutting and fatigue cracking parameters to draw conclusions about the effects despite these indicators having been developed for unmodified binders. They also relied on indicators calculated based on LVE limits which can give misleading results regarding the effects of these additives on bitumen characteristics, or studied impacts of the additives in conjunction with other materials such as polymers, tyre rubber or reclaimed asphalt. Accordingly, this paper aims to analyse the effects of two common WMA additives on bitumen rheology and performance at different critical temperatures, ageing conditions and additive dosages; and provide a better understanding and characterisation method of the impacts of these additives on bitumen performance.

\section{Materials and testing methods}

\subsection{Materials}

In this study, a 40/60 penetration grade bitumen with $49 \mathrm{dmm}$ penetration was used as a base binder $(\mathrm{Bb})$. Two WMA additives were used to modify the neat binder. The first was an organic additive known commercially as Sasobit. This additive is a synthetic wax produced by Sasol company; it works by reducing bitumen viscosity at temperatures beyond its melting point. This additive can increase asphalt stiffness and strength due to its bitumen stiffening effects [30]. Three dosages of this additive were considered in this study; $0.5 \%, 2 \%$, and $3.5 \%$ of bitumen weight (referred to as $0.5 \% \mathrm{OMB}, 2 \% \mathrm{OMB}$ and $3.5 \% \mathrm{OMB}$ respectively). These dosages were selected to study the effects of this additive at low, intermediate (which is the most common) and high dosages on bitumen characteristics. The second one was a chemical additive know commercially as Cecabase. This is a chemical WMA additive produced by Arkema group 
consisting of a liquid surfactant that works by reducing the surface tension of bitumen, which allows for the production of WMA at temperatures approximately $30-40{ }^{\circ} \mathrm{C}$ lower than reference HMA. It enhances mixture workability and compaction, even with the incorporation of high RAP percentages [31]. This additive was also added at three percentages; $0.2 \%$, $0.4 \%$, and $0.6 \%$ of binder weight (referred to as $0.2 \% \mathrm{CMB}, 0.4 \% \mathrm{CMB}$ and $0.6 \% \mathrm{CMB}$ ). The second dose is the recommended one, while the first and third dosages were included to study the influence of this additive at low and high modification levels. Some physical and chemical properties of both additives are presented in Table 1. Both additives were blended with the base binder by heating the base binder to $160{ }^{\circ} \mathrm{C}$ and then adding the required binder weight to a vessel containing the required additive dose to ensure accurate mixing proportions. The materials were immediately blended using a shear mixer at a low shear rate of $500 \mathrm{rpm}$ for $5 \mathrm{~min}$ to achieve homogeneous blending $[32,33]$. During the mixing process, the $\mathrm{Bb}$ was kept in an oven at the same mixing temperature to assure comparable ageing to the modified binders. To achieve the aims of this study, the methodology illustrated in Fig. 1 and detailed in Table 2 was carried out.

\subsection{Testing methods}

\subsubsection{Frequency sweep}

LVE properties of the studied binders were assessed by conducting a frequency sweep test using a Gemini $^{\text {TM }}$ DSR. The test was conducted in strain-controlled mode with $0.1 \%$ strain level over a temperature range from 0 to $80^{\circ} \mathrm{C}$; eleven oscillatory loading frequencies between 0.1 and $10 \mathrm{~Hz}$ were applied. The test was run from the lowest temperature and highest frequency to assure that the tested specimens were not damaged during testing. The tests were also conducted at three binder ageing levels (unaged, short term aged and combined short and long term ageing) in order to monitor any effects of the additives on changes in the rheological properties with ageing. The collected complex shear modulus and phase angle data were used to produce master curves by applying the TimeTemperature Superposition Principle (TTSP) [34]. After that, the 2S2P1D model [35] was fitted to the data to model the rheological properties of the different binders. This model was selected due to its ability to accurately describe the LVE characteristics of different types of binders [36].

\subsubsection{Multiple stress creep and recovery (MSCR)}

This test is conducted in the non-linear viscoelastic region since the strain levels in the test exceed the limits of LVE. Technically, it can be considered as a replacement for the original SHRP parameter $G^{*} / \sin \delta$ in the characterisation of modified binders since the latter was developed principally for unmodified bitumen. The MSCR test was developed based on creep studies during the NCHRP 9-10 project [15]. The test can be conducted using a DSR for unaged or shortterm aged binders at the high-performance grade temperature [37]. The test was conducted in compliance with the standard BS EN 16659:2015 [38]. The test consists of applying ten consecutive cycles of creep and recovery; the creep part lasting for one second under constant shear stress followed by nine seconds for recovery. The test was conducted at 30, 40, 50 and $60{ }^{\circ} \mathrm{C}$ and under two stress levels, 0.1 and
Table 1 Some physical and chemical properties of the studied additives

\begin{tabular}{lll}
\hline Property & Sasobit & Cecabase \\
\hline Physical condition at ambient temperature & Solid prills & Liquid \\
Colour & Off white & Light yellow \\
Odor & Odorless & Not available \\
Flash point & $290{ }^{\circ} \mathrm{C}$ & $178^{\circ} \mathrm{C}$ \\
Solidification temperature & $\sim 100{ }^{\circ} \mathrm{C}$ & $-10{ }^{\circ} \mathrm{C}$ \\
Density & $590 \mathrm{~kg} / \mathrm{m}^{3}$ (prills density) & $1000 \mathrm{~kg} / \mathrm{m}^{3}$ \\
Water solubility & Insoluble & Insoluble \\
Brookfield viscosity at $25{ }^{\circ} \mathrm{C}$ & Not applicable & $600 \mathrm{cP}$ \\
Melting point & $>100{ }^{\circ} \mathrm{C}$ & Not applicable \\
\hline
\end{tabular}




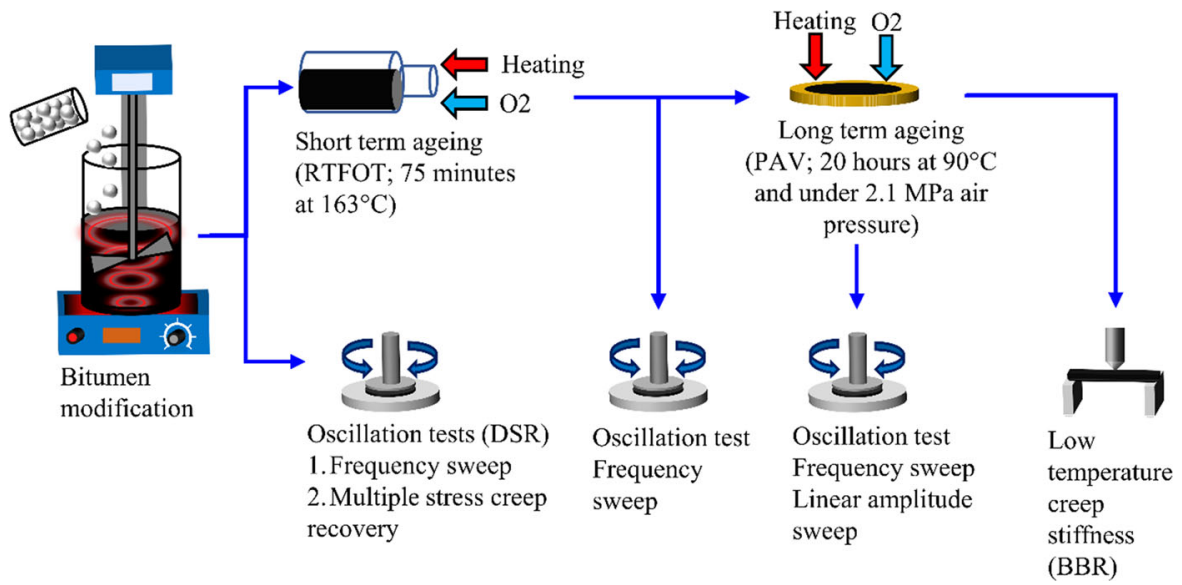

Fig. 1 Schematic diagram illustrating the methodology of the study

Table 2 Experimental plan

\begin{tabular}{|c|c|c|c|c|}
\hline Experiment & Standard & Equipment & Test temperature range $\left({ }^{\circ} \mathrm{C}\right)$ & Ageing condition \\
\hline Frequency sweep & BS EN 14770:2012 & DSR & $0-80$ & Unaged \\
\hline Multiple stress creep and recovery & BS EN 16659:2015 & DSR & $30,40,50,60$ & Unaged \\
\hline Frequency sweep & BS EN 14770:2012 & DSR & $0-80$ & RTFOT \\
\hline Frequency sweep & BS EN 14770:2012 & DSR & $0-80$ & RTFOT + PAV \\
\hline Low temperature creep stiffness & BS EN 14771:2012 & BBR & $-6,-12,-18$ & RTFOT + PAV \\
\hline Linear amplitude sweep & AASHTO TP 101-14 & DSR & 19 & RTFOT + PAV \\
\hline
\end{tabular}

$3.2 \mathrm{kPa}$, to analyse the stress sensitivity of the studied binders. The non-recoverable creep compliance was calculated as follows:

$J_{\mathrm{nr}}^{n}=\left(\varepsilon_{r}^{n}-\varepsilon_{i}^{n}\right) / \tau$

where $\varepsilon_{r}^{n}$ is the irrecoverable strain which is the strain value at the end of the recovery phase of cycle $n$ and $\varepsilon_{i}^{n}$ is the initial strain value at the start of cycle $n, \tau$ is the applied shear stress $\mathrm{kPa}$, and $J_{\mathrm{nr}}$ is the non-recoverable creep compliance $\mathrm{kPa}^{-1}$.

\subsubsection{Linear amplitude sweep (LAS)}

This test was developed based on Viscoelastic Continuum Damage (VECD) principles as an accelerated method to quantify fatigue life of asphalt from bitumen testing [39]. Currently, this test is a standard AASHTO procedure to evaluate and predict fatigue life due to the repeatability of testing results, simplicity and speed of the test. The test is performed in two stages using a DSR and an $8 \mathrm{~mm}$ parallel plate (spindle) geometry. The first stage is to determine the viscoelastic properties $\left(G^{*}\right.$ and $\delta$ ) and the energy release rate $(\alpha)$ of the intact material in the LVE zone. This can be done by performing a frequency sweep test at the test temperature. The second stage is to subject the same bitumen specimen to a linear strain sweep of an increasing amplitude from $0.1 \%$ to $30 \%$. [40]. The fatigue damage at any cycle can be determined as follows [41]:

$D(t)=\sum_{i=1}^{N}\left[\pi \gamma_{i}^{2}\left(\frac{\left|G^{*}\right|_{i-1}-\left|G^{*}\right|_{i}}{\left|G^{*}\right|_{i}}\right)\right]^{\frac{\alpha}{1+\alpha}} \times\left(t_{i}-t_{i-1}\right)^{\frac{1}{1+\alpha}}$

where $D(t)$ is the fatigue damage as a function of time, $\gamma_{i}$ applied strain for a given data point, and $t$ is time. The fatigue failure zone can be identified when the applied shear stress reaches its peak zone as suggested 
in the literature [42, 43]; and fatigue life can be calculated as a function of the maximum expected strain as follows:

$N_{f}=A \times\left(\gamma_{\max }\right)^{B}$

$A=\frac{f \times\left(D_{f}\right)^{k}}{k \times\left(\pi \times C_{1} \times C_{2}\right)^{\alpha}}$

$k=1+\left(1-C_{2}\right) \times \alpha$

$B=2 \times \alpha$

where $N_{f}$ is the predicted number of load applications until failure, $\gamma_{\max }$ is the maximum expected strain, $D_{f}$ is fatigue damage at the peak of the applied shear stress, and $A, k, B, C 1$ and $C 2$ are model parameters.

\subsubsection{Low-temperature creep stiffness (LTCS)}

Low temperature cracking susceptibility of asphalt pavements has been attributed to the high creep stiffness associated with inadequate relaxation of the thermal stresses of binders at low temperatures. In this study, the creep stiffness (S) and the creep relaxation modulus (m-value) were determined at three critical low temperatures, $-6,-12$, and $-18^{\circ} \mathrm{C}$ using a Bending Beam Rheometer (BBR) in accordance with the standard BS EN 14771:2012 [44].

\section{Results and discussion}

\subsection{Rheology of WMA-modified binders}

The effects of the applied additives on the shear modulus and the phase angle of the unaged base binder are presented in Fig. 2. The results are coded as follows: $X \%$ refers to the additive dose, then $\mathrm{C}$ or $\mathrm{O}$ refers to the type of the additive whether Chemical or Organic and MB stands for Modified Bitumen; whereas $\mathrm{Bb}$ stands for the Base binder. For clarity, only $0.4 \% \mathrm{CMB}$ is shown in Fig. 2 since the effect of the other two dosages was similar to this one. Also $0.5 \%$ OMB was not plotted for the same reason. The master curves in Fig. 2 indicate that the chemical additive did not change the complex modulus or the phase angle of the unaged binder regardless of additive dosage. The organic additive, however, significantly



Fig. 2 Complex shear modulus and phase angle master curves of the studied binders at a reference temperature of $40{ }^{\circ} \mathrm{C}$

impacted both of these properties with the higher the additive dosage, the higher the complex modulus and the lower the phase angle. These results indicate that this additive has a direct effect on binder rheology by stiffening the binder and imparting increased elastic response. However, the LVE frequency sweep tests were unable to detect any influence of the chemical additive on bitumen properties.

\subsection{Effect of additives on bitumen ageing}

To evaluate the impact of the additives on binder rheology at different ageing levels, frequency sweep tests were also conducted after short-term ageing in the rolling thin film oven test (RTFOT) [45] and longterm ageing in a pressure ageing vessel (PAV) [46]. The viscoelastic properties, $G^{*}$ and $\delta$, were then monitored and compared with the base binder, as shown in Figs. 3 and 4 at a temperature of $70{ }^{\circ} \mathrm{C}$ and



Fig. $3 G^{*}$ results at $70{ }^{\circ} \mathrm{C}$ and $10 \mathrm{~Hz}$ at different ageing conditions 


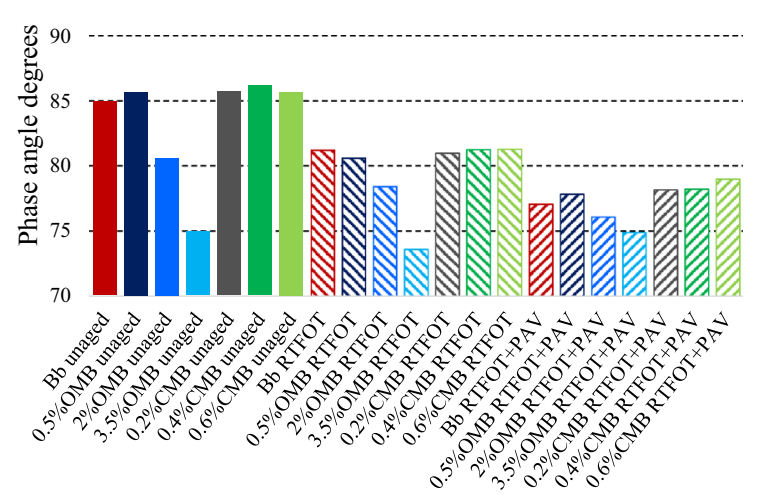

Fig. $4 \delta$ results at $70{ }^{\circ} \mathrm{C}$ and $10 \mathrm{~Hz}$ at different ageing conditions

frequency of $10 \mathrm{~Hz}$. The results generally show an increase in the complex shear modulus and a decrease in the phase angle of all binders with ageing. The presence of the additives, however, has affected the rate of change of these properties over the ageing stages.

On the one hand, the organic additive increased $G^{*}$ and reduced $\delta$ after modification, and this impact is directly correlated with the dosage of the additive. However, after combined short and long-term ageing, the $G^{*}$ results of OMBs are relatively comparable to those of the base binder. The same trend can be seen for $\delta$, despite the significant difference between the $\mathrm{Bb}$ phase angle and that of the OMBs before ageing. However, after the combined ageing stages, the difference becomes less, and the $\delta$ results are relatively comparable to each other. Therefore, it can be concluded that this additive has the potential to improve rutting resistance due to the increase in the complex shear modulus after no or short-term ageing. On the other hand, the chemical additive generally maintained $\delta$ similar to $\mathrm{Bb}$ at all ageing levels, but it significantly retarded the effect of ageing with respect to the complex modulus after both short and long-term ageing. It is believed that the reason behind this result is the chemical effect of the additive on bitumen oxidative ageing compared to the ageing taking place for base bitumen. This result could be interpreted as an improvement in cracking resistance after long-term ageing [47].

Furthermore, since the effect of ageing tends to effect fatigue resistance, the critical intermediate temperature derived from the Superpave fatigue cracking parameter was used to analyse the ageing effect of the additives. The results are presented in Fig. 5. This figure indicates that the critical intermediate temperature generally increases with ageing, which means that the susceptibility of bitumen to exhibit fatigue cracking also increases with ageing. The base bitumen critical temperatures are 14.5, 16.8, and $26.6{ }^{\circ} \mathrm{C}$ after no ageing, short-term ageing, and combined short and long-term ageing, respectively. However, the presence of additives changed the rate of increase of this temperature over the ageing stages. Initially, the OMBs exhibited slightly higher critical temperatures than that of the base binder, whereas the CMBs showed slightly lower critical temperatures. However, after the combined ageing stages, all the modified binders exhibited critical temperatures between 18 and $21{ }^{\circ} \mathrm{C}$, significantly lower than that of the base binder. This confirms that the investigated additives retard bitumen ageing which can alter the mechanical performance of WMAs produced with these additives.

\subsection{MSCR results}

This test was conducted using a Gemini ${ }^{\mathrm{TM}}$ DSR at temperatures of $30,40,50$, and $60{ }^{\circ} \mathrm{C}$ under unaged binder conditions. Figure 6 presents the creep and recovery results at $40{ }^{\circ} \mathrm{C}$ and $3.2 \mathrm{kPa}$ stress, which demonstrate that the organic additive reduced shear strain, whereas the chemical additive slightly increased it. The figure shows that there are two different mechanisms through which the additives can alter bitumen response to the applied stress. Firstly, by changing bitumen stiffness which results in a decrease

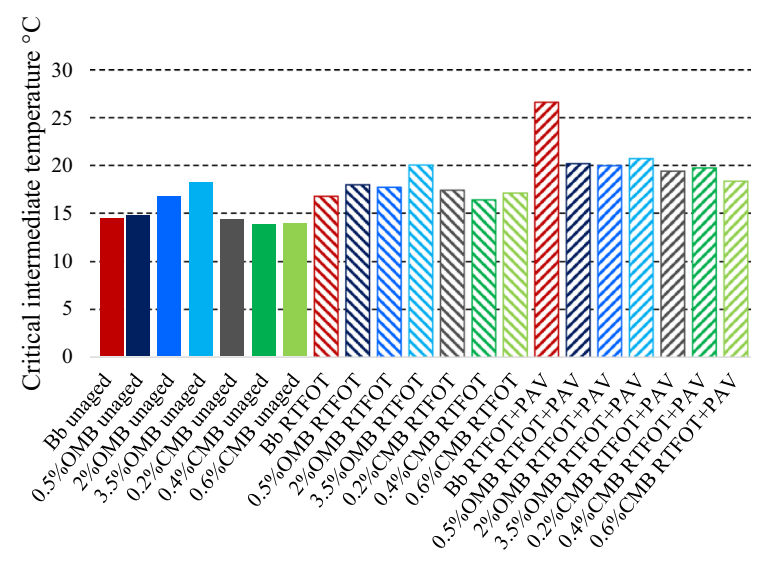

Fig. 5 Critical intermediate temperatures of the analysed binders 


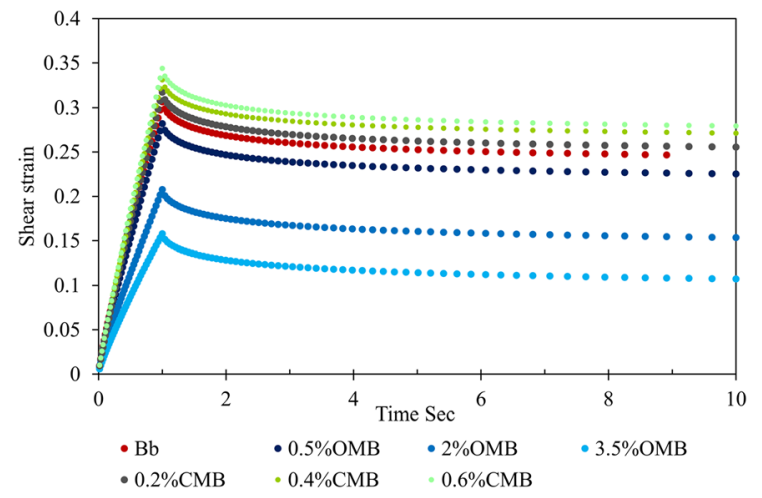

Fig. 6 Creep and recovery of the studied binders at $40{ }^{\circ} \mathrm{C}$ and $3.2 \mathrm{kPa}$ loading stress

or increase in the resultant strain after the loading period relative to the base bitumen. Secondly, by impacting the bitumen recovery properties, which means altering the ability of the bitumen to recover strain after the load is removed. These two mechanisms can be decoupled to better understand the impact of the additives.

The creep component was studied by isolating the creep results at the end of the loading period $(1 \mathrm{~s}$.) and then normalising the results for the modified binders at each temperature against the base binder creep results, as shown in Fig. 7. This figure demonstrates that the organic additive significantly reduced the creep strain, and this reduction is directly related to the additive dosage with the higher the additive concentration, the more significant the reduction. In contrast, the chemical additive slightly increased the creep strain by approximately $2-10 \%$ at all testing temperatures. The recovery component was analysed similarly by calculating recovered strain and then normalising the results

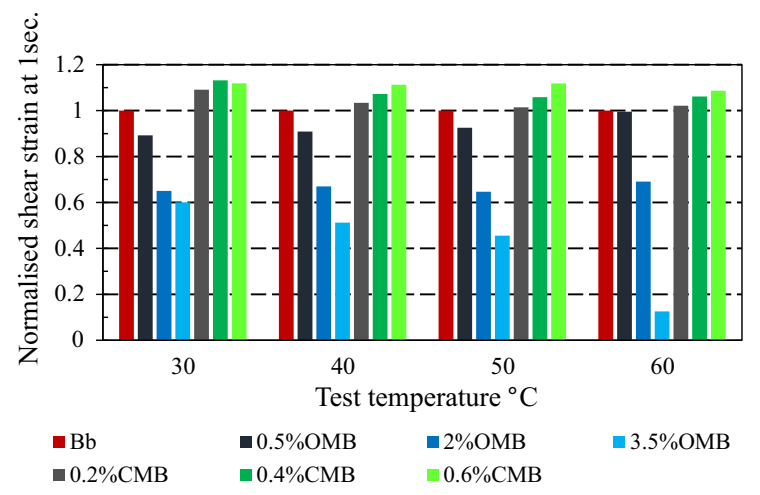

Fig. 7 Normalised creep strain results at 1 s. of loading against the base binder results at each testing temperature, as shown in Fig. 8. This figure indicates that the organic additive significantly improved the creep recovery properties at intermediate and high dosages. This improvement is also related to the additive concentration; the higher the dosage, the greater the improvement. Also, it can be observed that the additive impact is more significant at higher temperatures such as 50 and $60{ }^{\circ} \mathrm{C}$. This can be explained by the fact that at these temperatures, the $\mathrm{Bb}$ is approaching its critical high temperature which leads to larger permanent strains. This means that the additive effects can be realised at critical temperatures where the base binder is tested at its limits. Meanwhile, the chemical additive very slightly reduced creep recovery.

Furthermore, the $\mathrm{J}_{\mathrm{nr}}$, which is the outcome of the combined effect of the two mechanisms (bitumen stiffness and creep recovery), was calculated according to Eq. 1 and presented in Fig. 9, again normalised against the base binder. This figure confirms the conclusion that the organic additive is likely to significantly improve permanent deformation resistance at intermediate and high dosages, whereas the chemical additive slightly reduces this property. However, by uncoupling the creep stage from the recovery stage, it becomes clear how these additives alter these bitumen rheological properties. The organic additive significantly increases bitumen stiffness and increases its creep recovery properties, which leads to a better rutting resistance. On the other hand, the chemical additive can increase bitumen susceptibility to permanent deformation, mainly due to marginally reducing its stiffness, which results in an increased creep compliance magnitude.

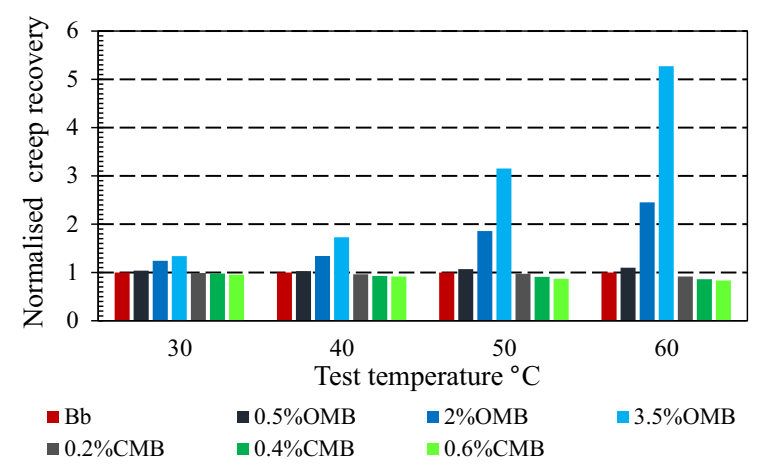

Fig. 8 Normalised creep recovery results 


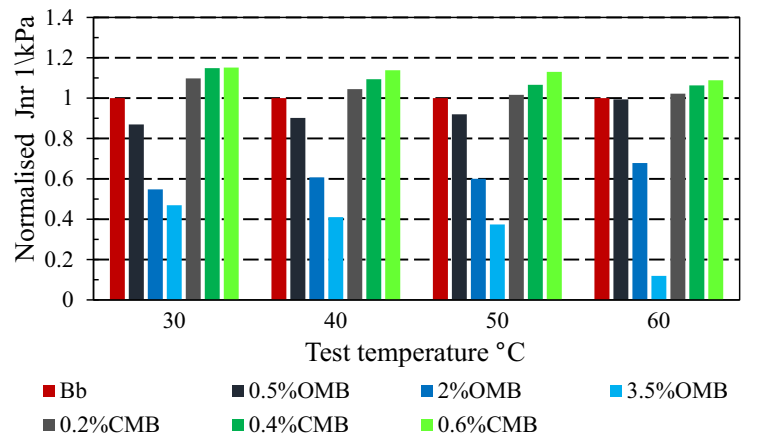

Fig. $9 \mathrm{~J}_{\mathrm{nr}}$ normalised results

\subsection{LAS results}

This test was conducted using a Gemini ${ }^{\mathrm{TM}}$ DSR at an intermediate temperature of $19^{\circ} \mathrm{C}$ using an $8 \mathrm{~mm}$ parallel plate (spindle) geometry. The test temperature was selected because all the modified binders exhibited an approximate critical intermediate temperature of $19{ }^{\circ} \mathrm{C}$ [41]. The relationship between shear stress and strain is presented in Fig. 10. The figure indicates that the shear stress is increasing with increasing strain amplitude until the sample fails with the failure zone being determined by the sharp drop in the shear stress after failure takes place. This figure shows that the OMBs require higher stress to achieve the required strain, which correlates with the stiffening effect of this additive. On the other hand, the CMBs have lower shear stress as a function of applied strain due to the slight reduction in the shear modulus due to the presence of the chemical additive. To add meaning to these observations, the number of load applications to failure at different strain levels was predicted using Eq. 2, as shown in Fig. 11. This figure demonstrates

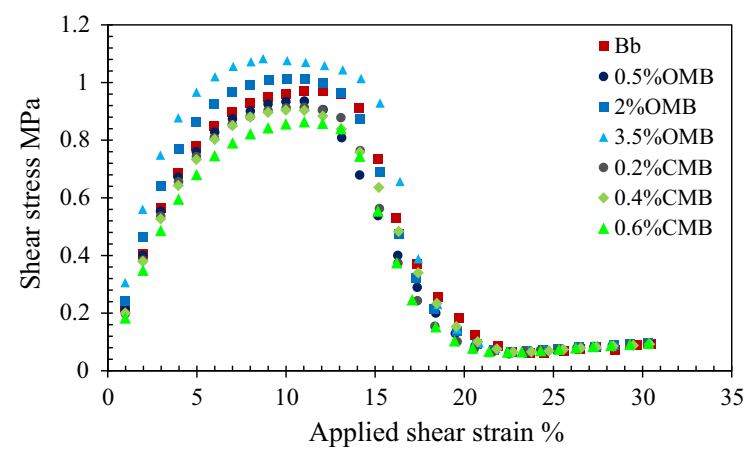

Fig. 10 Identification of failure zone by the peak shear stress method

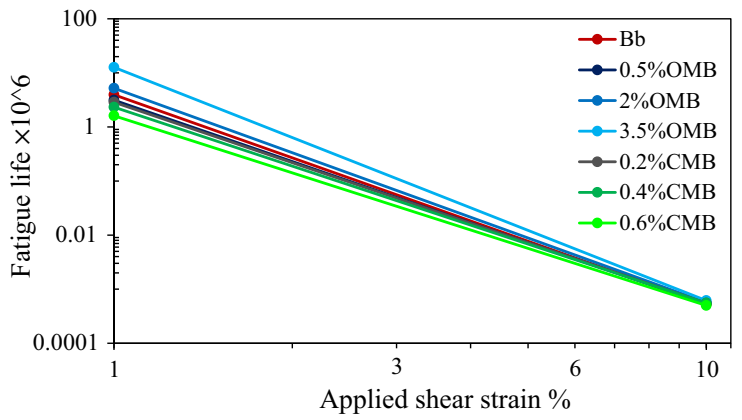

Fig. 11 Fatigue lines of the studied binders

that at low dosages of the additives, there is only a marginal change in the fatigue performance of the modified binders relative to the base bitumen. However, if higher dosages are used, then bitumen fatigue performance can significantly change with the high dosage of the organic additive having the potential to improve fatigue life, whereas the chemical additive can shorten it.

By comparing the results in Figs. 5 and 11, it can be seen that the Superpave fatigue cracking parameter indicated that all the modified binders (organic and chemical additives) are likely to improve fatigue performance after ageing since the critical intermediate temperatures of the modified binders were about $\sim 6$ to $7^{\circ} \mathrm{C}$ lower than that of the base binder. However, the LAS results indicated that only the organic additive improved fatigue life while the chemical additive reduced it. To further tackle this disagreement, the $\mathrm{G}-\mathrm{R}$ parameter was calculated and included in the analysis. This parameter was derived from the relationship between bitumen ductility at $15{ }^{\circ} \mathrm{C}$ and bitumen $G^{*}$ and $\delta$ (at $15^{\circ} \mathrm{C}$ and a radial frequency of $0.005 \mathrm{rad} / \mathrm{sec}$ ) established by Glover, Davison [48] and calculated from DSR frequency sweep results. Previous studies have also shown that the $\mathrm{G}-\mathrm{R}$ parameter is a good indicator of fatigue cracking when assessed against laboratory and field performance of asphalt mixtures $[49,50]$. The $\mathrm{G}-\mathrm{R}$ parameter can be calculated as follows:

$\mathrm{G}-\mathrm{R}=\frac{G^{*} \times(\cos \delta)^{2}}{\sin \delta}$

To calculate this parameter, the 2S2P1D model was firstly fitted to the $G^{*}$ and $\delta$ master curves in order to accurately determine these parameters at a 
temperature of $15^{\circ} \mathrm{C}$ and a frequency of $0.005 \mathrm{rad} / \mathrm{s}$. The 2S2P1D model has the following mathematical form [35]:

$G^{*}(\omega)=G_{0}+\frac{G_{g}-G_{0}}{1+\alpha(i \omega \tau)^{-k}+(i \omega \tau)^{-h}+(i \omega \beta \tau)^{-1}}$

where $G_{\mathrm{g}}$ is the glassy modulus, $G_{0}$ is the equilibrium modulus, $\beta, \tau, \alpha, k$, and $h$ are model parameters that can be calculated by an optimisation process. Model parameters were determined using the optimisation function "Solver" embedded in Excel software with the results shown in Table 3. By using this model, the shear modulus and phase angle were calculated for all binders at $15{ }^{\circ} \mathrm{C}$ and $0.005 \mathrm{rad} / \mathrm{sec}$ and the G-R parameter was then calculated using Eq. 7. The results are presented in Figs. 12 and 13. The first figure shows that the G-R parameter increases with ageing, which can be interpreted as the cracking potential increasing due to the reduction in the ductility of the bitumen. The second figure presents the G-R parameter results in a Black space diagram plotted against the suggested threshold value of $180 \mathrm{kPa}$. This value is associated with the onset of cracking that was linked to a binder ductility of $50 \mathrm{~mm}$ [51]. Figure 13 shows that all of the investigated binders were expected to perform acceptably concerning fatigue cracking when considering the "pass-fail" criterion suggested by Rowe [51]. The figure also shows that the $3.5 \% \mathrm{OMB}$ is the closest binder to the failure zone, whereas the CMBs are the lowest susceptible binders to cracking.

These results, however, disagree with the LAS test results since the latter showed the opposite behavior. Figure 14 presents a correlation between LAS and G$\mathrm{R}$ results which demonstrates that the increase in the G-R values contributes to improved fatigue life. Accordingly, it can be concluded that lower G-R

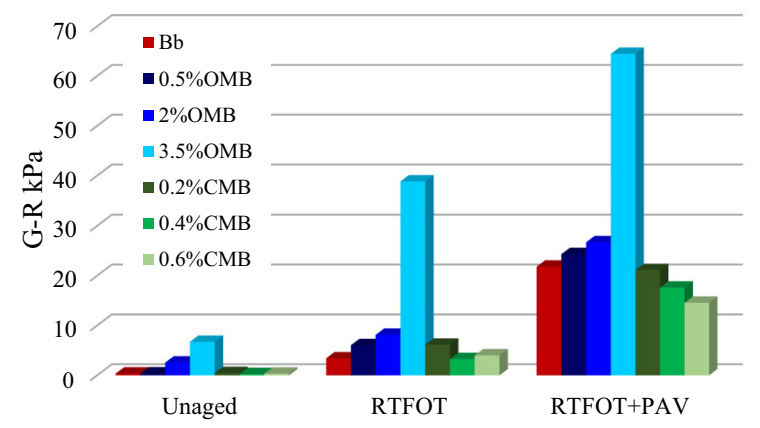

Fig. 12 G-R magnitude at different binder ageing levels

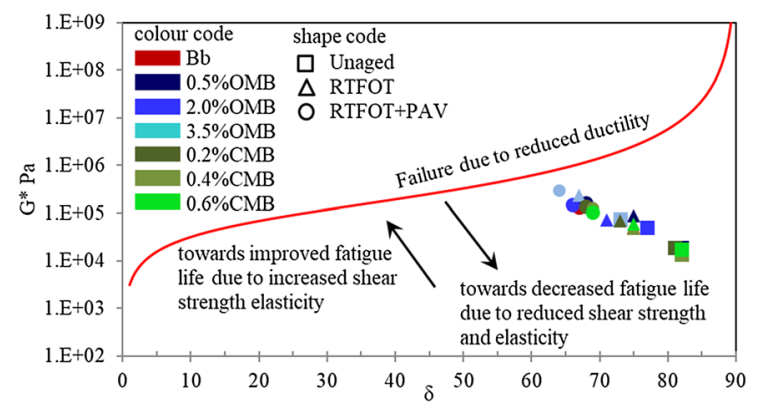

Fig. 13 G-R results plotted on a black diagram

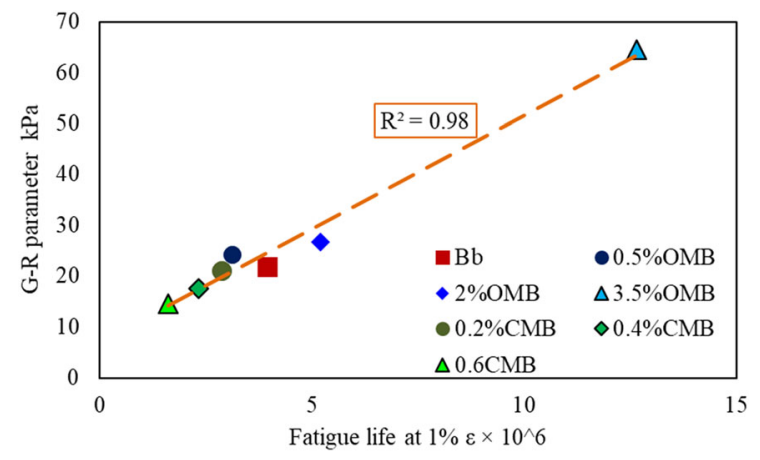

Fig. 14 Correlation between LAS and G-R results
Table 3 2S2P1D model parameters for the combined RTFOT and PAV ageing stage

\begin{tabular}{llllllll}
\hline Binderlparameter & $G_{0} \mathrm{~Pa}$ & $G_{\mathrm{g}} \mathrm{Pa}$ & $k$ & $h$ & $\tau$ & $\alpha$ & $\beta$ \\
\hline $\mathrm{Bb}$ & 0 & $1 \mathrm{E}+09$ & 0.39 & 0.86 & $2 \mathrm{E}-05$ & 23.55 & 90 \\
$0.5 \% \mathrm{OMB}$ & 0 & $1 \mathrm{E}+09$ & 0.39 & 0.87 & $2 \mathrm{E}-05$ & 21.92 & 90 \\
$2 \% \mathrm{OMB}$ & 0 & $1 \mathrm{E}+09$ & 0.41 & 0.89 & $2 \mathrm{E}-05$ & 25.19 & 90 \\
$3.5 \% \mathrm{OMB}$ & 0 & $1 \mathrm{E}+09$ & 0.40 & 0.88 & $4 \mathrm{E}-05$ & 28.78 & 90 \\
$0.2 \% \mathrm{CMB}$ & 0 & $1 \mathrm{E}+09$ & 0.42 & 0.90 & $2 \mathrm{E}-05$ & 28.37 & 90 \\
$0.4 \% \mathrm{CMB}$ & 0 & $1 \mathrm{E}+09$ & 0.44 & 0.91 & $3 \mathrm{E}-05$ & 25.59 & 90 \\
$0.6 \% \mathrm{CMB}$ & 0 & $1 \mathrm{E}+09$ & 0.41 & 0.89 & $1 \mathrm{E}-05$ & 25.00 & 90 \\
\hline
\end{tabular}


values may not necessarily contribute to better fatigue life. To explain this conclusion, the zones of high viscosity and low shear strength on the Black space diagram shown in Fig. 13 must be considered in the analysis. Reduced shear strength associated with increased viscous behavior contributes to increased shear strains and prolonged strain damaged time, which can lead to reduced fatigue life. On the other hand, reduced bitumen ductility leads to reduced strain tolerance and stress relaxation, which also leads to retarded fatigue life. Accordingly, it can be concluded that fatigue performance is related to several factors acting at the same time; balancing these parameters is the key to improve and maintain acceptable fatigue performance. Moreover, the overall conclusion of these results is that fatigue life can be enhanced by increasing bitumen shear modulus and elasticity while maintaining an adequate ductility level.

\subsection{Low-temperature creep stiffness}

Figure 15 presents the LTCS results in terms of $S$ value and $m$-value following the Superpave requirements. The results show a clear trend of increased susceptibility to low temperature cracking in the case of the OMBs due to the presence of the organic additive with increased bitumen stiffness and reduced $\mathrm{m}$-value. This means that this bitumen becomes more prone to cracking at low temperatures. Also, this trend is directly related to the additive dosage; the higher the dosage, the higher the S-value and the lower the $\mathrm{m}$-value. On the other hand, Fig. 15 indicates that the CMBs can improve performance regarding low temperature cracking because this additive reduced the stiffness and increased the relaxation properties of the bitumen. This effect seems to be again directly related to the additive dosage; the higher the dose, the more significant the impact. This means that the presence of the chemical additive can enhance the low temperature cracking and this finding can be attributed to the ageing retardation capability of the chemical additive.

Previous studies have also plotted BBR results in a Black space diagram to assess the low temperature cracking susceptibility of asphalt binders and mixtures $[50,52,53]$. To apply this method, the stiffness and $\mathrm{m}$-value results were plotted in a Black diagram by assuming that the phase angle is represented by the $\mathrm{m}$-value as explained by Romero [52], as shown in Fig. 16. The red shaded area represents the zone where the binder is susceptible to low temperature cracking. Conversely, the green area represents the zone where the binder performs acceptably. This figure shows that the tested binders formed three distinct groups representing the three testing temperatures with the
Fig. 15 Stiffness and $\mathrm{m}$-value results from the BBR

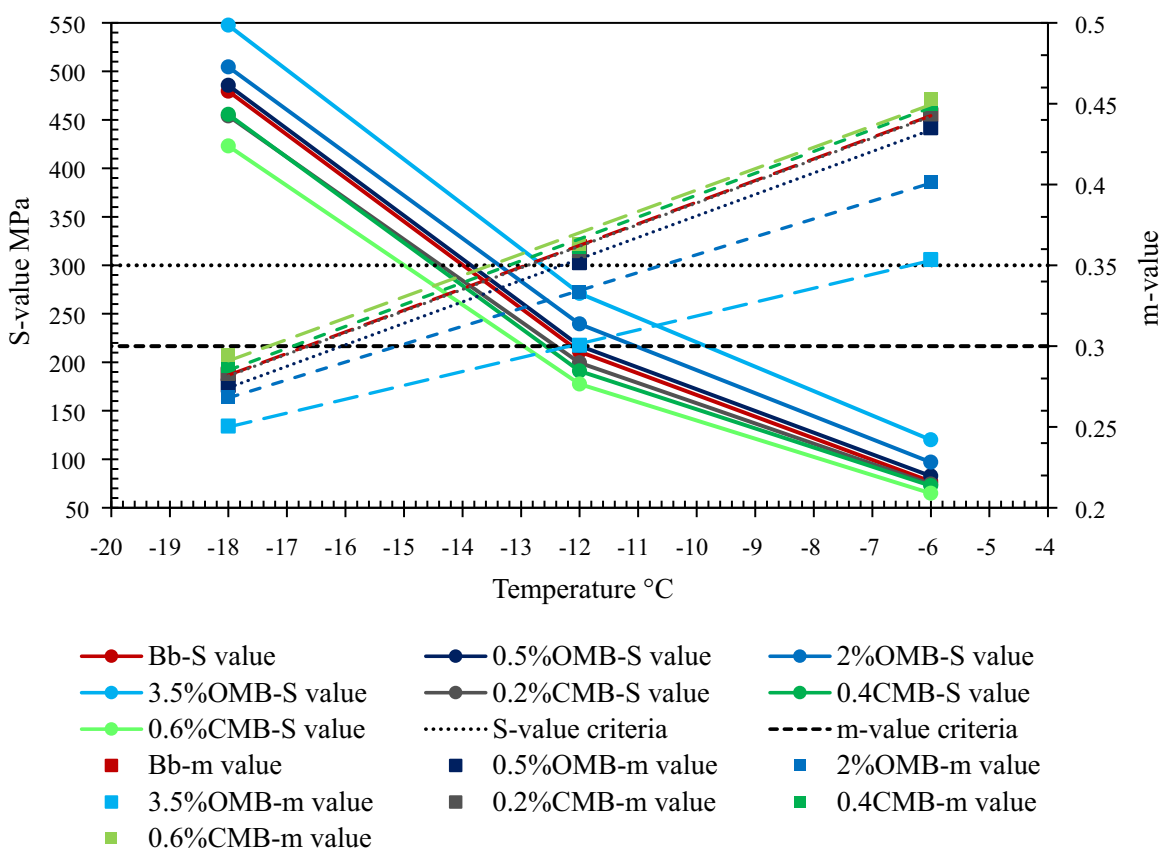




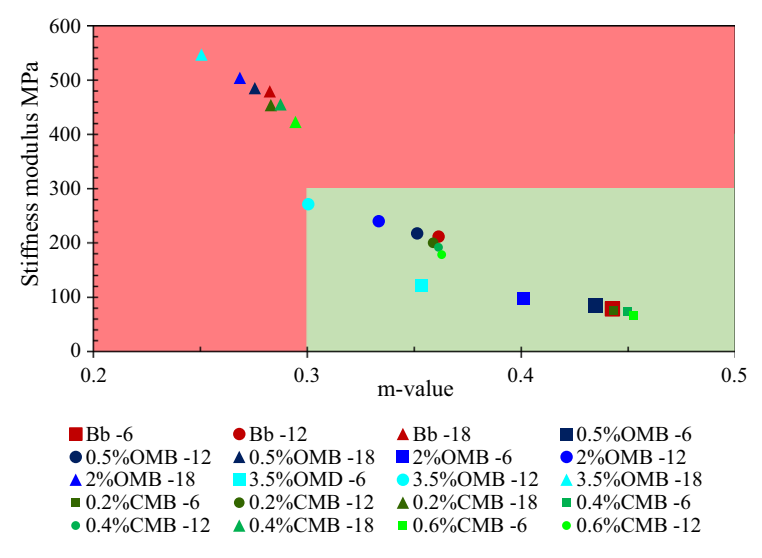

Fig. 16 Black diagram of the BBR results

stiffness increasing and m-value decreasing; as the test temperature increases. The figure also confirms the previous finding of increased binder stiffness and reduced relaxation in the case of the organic additive and decreased binder stiffness and increased relaxation in the case of the chemical additive.

\section{Summary and conclusions}

The primary aim of this study was to evaluate and understand the influence of two representative organic and chemical WMA additives on bitumen rheology and performance. The rheological characteristics were studied at different critical temperatures using the DSR and BBR. Frequency sweep, MSCR, LAS and LTCS tests were conducted to analyse the behavior of the modified binders at different bitumen ageing levels. Based on the results of this study, the following conclusions can be drawn:

1. The frequency sweep results show that the organic additive has a bitumen stiffening effect, with this effect being directly related to the additive dosage. However, there was no noticeable effect on LVE rheological properties (stiffness and viscoelastic behavior) for the chemical additive when testing the modified binder in its unaged condition.

2. Despite the stiffening effect of the organic additive, the viscoelastic properties after RTFOT and PAV ageing were comparable to those of the base binder which means that this additive stiffens the binder after modification but can retard the ageing process. A similar effect in terms of ageing was seen for the CMBs with the chemical additive significantly retarding the bitumen ageing process resulting in the shear modulus being lower and the phase angle being higher compared to those of the base binder after the two ageing stages.

3. The Superpave fatigue cracking parameter also showed that the WMA additives (both organic and chemical additives) decreased bitumen ageing by retarding the increase in the critical intermediate temperature with ageing, which can be interpreted as an improvement in fatigue cracking performance after long-term ageing when WMA additives are incorporated.

4. The MSCR test results clearly show that the organic additive can improve rutting performance at high temperatures, whereas the chemical additive may slightly degrade it. Moreover, by uncoupling the creep component from the recovery stage, the mechanism by which these additives impact bitumen properties becomes clearer. The organic additive improved bitumen recovery as well as increased its stiffness, which led to better rutting resistance. On the other hand, the chemical additive increased bitumen susceptibility to permanent deformation by decreasing its stiffness and slightly decreasing its creep recovery properties.

5. The impact of the additives on bitumen fatigue life were investigated by two methods, namely the LAS test and G-R parameter. The LAS results showed that the presence of the organic additive can improve fatigue cracking of bitumen whilst the chemical additive may make it more prone to this distress. However, the G-R indicator showed the opposite behavior with the OMBs being the closest to the cracking failure criterion, whereas the CMBs were potentially the least susceptible to cracking. It was possible to establish an excellent correlation between LAS and G-R results which indicated that for the data set investigated in this paper that higher G-R values contributed to better fatigue life. It is postulated that there is a damage zone where low $\mathrm{G}-\mathrm{R}$ values contribute to reduced fatigue life due to the reduction in bitumen shear modulus and the increase in bitumen viscosity which may explain this correlation between LAS and $\mathrm{G}-\mathrm{R}$ results. This conclusion could be interpreted as fatigue life may improve over ageing due to the increasing elastic behavior until it reaches a 
critical zone where the material becomes increasingly brittle and strain-sensitive which causes a drop in fatigue life. This initial increase in fatigue performance with ageing (and increased G-R values) has been demonstrated in other relevant studies $[54,55]$.

6. The LTCS results demonstrated that the chemical additive can improve low temperature cracking performance because it reduces bitumen stiffness and increases its relaxation properties. The organic additive, however, was found to make the bitumen more susceptible to this failure mode because it increased bitumen stiffness and lowered its relaxation properties in comparison to the base binder. Furthermore, plotting LTCR results on a Black space diagram was shown to be an effective method to characterise low temperature cracking susceptibility of bitumen.

7. Considering the effects of the studied additives on bitumen characteristics, it is reasonable to assume that the chemical additive is more suitable for cold regions where low temperature cracking is a concern, whereas the organic additive is more effective for hot regions due to its positive effects on bitumen rutting resistance.

\section{Compliance with ethical standards}

Conflict of interest The authors declare that they have no conflict of interest.

Open Access This article is licensed under a Creative Commons Attribution 4.0 International License, which permits use, sharing, adaptation, distribution and reproduction in any medium or format, as long as you give appropriate credit to the original author(s) and the source, provide a link to the Creative Commons licence, and indicate if changes were made. The images or other third party material in this article are included in the article's Creative Commons licence, unless indicated otherwise in a credit line to the material. If material is not included in the article's Creative Commons licence and your intended use is not permitted by statutory regulation or exceeds the permitted use, you will need to obtain permission directly from the copyright holder. To view a copy of this licence, visit http://creativecommons.org/licenses/by/4.0/.

\section{References}

1. Perkins SW (2009) Synthesis of warm mix asphalt paving strategies for use in Montana highway construction. Western Transportation Institute, Montana State University (No. FHWA/MT-09-009/8117-38)
2. EAPA (2010) The use of warm mix asphalt. European Asphalt Pavement Association, Brussels

3. Sargand S et al (2009) Performance assessment of warm mix asphalt (WMA) pavement. Ohio Research Institute for Transportation and the Environment, Ohaio University, Athens

4. WMA TWG (2019) WMA technologies [cited 2019 4th November] http://www.warmmixasphalt.org/WmaTechnologies. aspx

5. Thom N (2014) Principles of pavement engineering, 2nd edn. ICE Publishing, London

6. D'Angelo J et al (2008) Warm mix asphalt: European practice. American Trade Initiatives, Washinton

7. Almeida-Costa A, Benta A (2016) Economic and environmental impact study of warm mix asphalt compared to hot mix asphalt. J Clean Prod 112:2308-2317

8. Abed A, Thom N, Grenfell J (2019) A novel approach for rational determination of warm mix asphalt production temperatures. Constr Build Mater 200:80-93

9. Polacco G et al (2012) Structural and rheological characterization of wax modified bitumens. Fuel 95:407-416

10. Yang S et al (2018) Effects of Sasobit and Deurex additives on asphalt binders at midrange and high temperatures. Int $\mathrm{J}$ Pavement Eng 20(12):1400-1407

11. Arega $Z$ et al (2011) Influence of warm-mix additives and reduced aging on the rheology of asphalt binders with different natural wax contents. J Mater Civ Eng 23(10):1453-1459

12. Xiao F, Punith VS, Amirkhanian SN (2012) Effects of nonfoaming WMA additives on asphalt binders at high performance temperatures. Fuel 94:144-155

13. Laukkanen O-V, Soenen H (2015) Rheological characterization of wax modified bituminous binders: effect of specimen preparation and thermal history. Constr Build Mater 95:269-278

14. Dondi G et al (2016) Evaluation of different short term aging procedures with neat, warm and modified binders. Constr Build Mater 106:282-289

15. Bahia $\mathrm{H}$ et al (2001) Characterization of modified asphalt bitumens in superpave mix design. National Academy Press, Washington

16. Bahia H, Wen H, Johnson CM (2010) Development in asphalt binder specifications: developments in intermediate temperature binder fatigue specifications. Transportation Research Board, Washington

17. Subhy A (2017) Advanced analytical techniques in fatigue and rutting related characterisations of modified bitumen: literature review. Constr Build Mater 156:28-45

18. Bahia HU et al (2001) Development of binder specification parameters based on characterization of damage behavior (with discussion). J Assoc Asphalt Paving Technol 70:442-470

19. Airey GD (2004) Fundamental binder and practical mixture evaluation of polymer modified bituminous materials. Int $\mathbf{J}$ Pavement Eng 5(3):137-151

20. Norouzi N, Ameli A, Babagoli R (2019) Investigation of fatigue behaviour of warm modified binders and warm-stone matrix asphalt (WSMA) mixtures through binder and mixture tests. Int J Pavement Eng. https://doi.org/10.1080/ 10298436.2019.1659262

21. Marasteanu M (2010) Development in asphalt binder specifications: low-temperature testing and specifications. Transportation Research Board, Washington 
22. Xu J et al (2020) Effects of warm mix additives on the thermal stress and ductile resistance of asphalt binders. Constr Build Mater 238:117746

23. Kim HH et al (2019) Effect of production process on performance properties of warm rubberized binders. J Traffic Transp Eng (Engl Ed) 6(6):589-597

24. Wen Y et al (2018) The engineering, economic, and environmental performance of terminal blend rubberized asphalt binders with wax-based warm mix additives. J Clean Prod 184:985-1001

25. Kumar R et al (2017) Effect of warm mix additives on creep and recovery response of conventional and polymer modified asphalt binders. Constr Build Mater 138:352-362

26. Liu J et al (2016) Laboratory performance of warm mix asphalt binder containing polyphosphoric acid. Constr Build Mater 106:218-227

27. Xiao F, Putman B, Amirkhanian S (2015) Rheological characteristics investigation of high percentage RAP binders with WMA technology at various aging states. Constr Build Mater 98:315-324

28. Kök BV, Y1lmaz M, Akpolat M (2014) Evaluation of the conventional and rheological properties of SBS + Sasobit modified binder. Constr Build Mater 63:174-179

29. Yan K-Z, Xu H-B, Zhang H-L (2013) Effect of mineral filler on properties of warm asphalt mastic containing Sasobit. Constr Build Mater 48:622-627

30. Abed A, Thom N, Grenfell J (2017) Evaluation of mixing temperature impact on warm mix asphalt performance. In: Tenth international conference on the bearing capacity of roads, railways and airfields. Athens, Greece

31. Arkema Group (2016) Cecabase RT [cited 2016 15/03] http://www.arkema.com/en/products/product-finder/rangeviewer/Cecabase-RT/

32. Hurley GC, Prowell BD (2005) Evaluation of Sasobit ${ }^{\circledR}$ for use in warm mix asphalt. NCAT, National Center of Asphalt Technology, Auburn University, Alabama

33. Biro S, Gandhi T, Amirkhanian S (2009) Determination of zero shear viscosity of warm asphalt binders. Constr Build Mater 23(5):2080-2086

34. Airey GD (1997) Rheological characteristics of polymer modified and aged bitumens. In: Department of Civil Engineering. The University of Nottingham

35. Olard F, Di Benedetto H (2011) General "2S2P1D" model and relation between the linear viscoelastic behaviours of bituminous binders and mixes. Road Mater Pavement Des 4(2):185-224

36. Md. Yusoff NI et al (2013) Modelling the rheological properties of bituminous binders using the 2S2P1D Model. Constr Build Mater 38:395-406

37. Soenen H et al (2013) The multiple stress creep-recovery test: a detailed analysis of repeatability and reproducibility. Road Mater Pavement Des 14(sup1):2-11

38. British Standards Institute (2015) BS EN 16659-2015, Bitumen and bituminous binders-multiple stress creep and recovery test (MSCRT). BSI, London

39. Kim Y et al (2006) A simple testing method to evaluate fatigue fracture and damage performance of asphalt mixtures. In: Asphalt Paving Technology: Association of Asphalt Paving Technologists-Proceedings of the Technical Sessions. Association of Asphalt Paving Technologist
40. Hintz C et al (2011) Modification and validation of linear amplitude sweep test for binder fatigue specification. Transp Res Rec J Transp Res Board 2207:99-106

41. AASHTO TP 101 (2014) Estimating damage tolerance of asphalt binders using the linear amplitude sweep. American Association of State Highway and Transportation Officials, Washington

42. Bahia H et al (2013) Field evaluation of Wisconsin modified binder selection guidelines-Phase II. Wisconsin Highway Research Program, Project: 0092-13-02

43. Micaelo R et al (2015) Fatigue resistance of asphalt binders: assessment of the analysis methods in strain-controlled tests. Constr Build Mater 98:703-712

44. BSI (2012) BS EN 14771:2012, Bitumen and bituminous binders-determination of the flexural creep stiffnessbending beam rheometer (BBR). British Standards Institution, London

45. BSI (2014) BS EN 12607-1:2014, Bitumen and bituminous binders - determination of the resistance to hardening under influence of heat and air Part 1: RTFOT method. British Standards Institution, London

46. BSI (2012) BS EN 14769-2012, Bitumen and bituminous binders-accelerated long-term ageing conditioning by a pressure ageing vessel (PAV). British Standards Institution, London

47. Walubita LF et al (2006) Computation of pseudo strain energy and Paris law fracture coefficients from surface energy and uniaxial strain-controlled tension test data. Int J Pavement Eng 7(3):167-178

48. Glover CJ et al (2005) Development of a new method for assessing asphalt binder durability with field validation. Texas Dept Transp 1872:1-334

49. Makowska M, Aromaa K, Pellinen T (2017) The rheological transformation of bitumen during the recycling of repetitively aged asphalt pavement. Road Mater Pavement Des 18(sup2):50-65

50. Mensching DJ et al (2015) Exploring low-temperature performance in Black Space. Road Mater Pavement Des 16(sup2):230-253

51. Rowe G (2011) Prepared discussion following the Anderson AAPT paper cited previously. In: AAPT

52. Romero P (2016) Using the bending beam rheometer for low temperature testing of asphalt mixtures. The University of Utah, Department of Civil and Environmental Engineering, 110 Central Campus Drive, Suite 2000, Salt Lake City, p 84112

53. Rowe G (2014) Interrelationships in rheology for asphalt binder specifications. In: Proceedings of the fifty-ninth annual conference of the canadian technical asphalt association (CTAA): Winnipeg, Manitoba

54. Hintz $C$ et al (2011) Effect of oxidative aging on binder fatigue performance. J Assoc Asphalt Paving Technol 80:527-548

55. Jing R et al (2019) Rheological, fatigue and relaxation properties of aged bitumen. Int J Pavement Eng. https://doi. org/10.1080/10298436.2019.1654609

Publisher's Note Springer Nature remains neutral with regard to jurisdictional claims in published maps and institutional affiliations. 